\title{
AN ASSESSMENT OF ANTIBACTERIAL TREATMENT USED ALONE OR IN ASSOCIATION WITH SURGICAL OPERATION IN THE TREATMENT OF PULMONARY TUBERCULOSIS
}

\author{
BY
}

\author{
J. R. EDGE, W. H. HELM, M. R. GEAKE, AND R. L. WARD \\ From Manchester Regional Hospital Board
}

(RECEIVED FOR PUBLICATION SEPTEMBER 16, 1960)

The discovery of streptomycin by Schatz, Bugie, and Waksman (1944), followed by the introduction of para-amino salicylic acid (P.A.S.) (Lehmann, 1946) and of isoniazid (Robitzek and Selikoff, 1952), completely revolutionized the treatment of pulmonary tuberculosis. With preliminary antibacterial treatment using combinations of these agents, artificial pneumothorax and thoracoplasty became relatively safe procedures and shorter periods of bed rest were necessary. The results of surgical resection improved enormously, with a high proportion of successes and a low complication rate (Bickford, Edwards, Esplen, Gifford, and Thomas, 1952 ; Thompson, Savage, and Rosser, 1954), and operation came to be regarded as an essential part of treatment in most patients with extensive disease unsuitable for, or inadequately controlled by, other means. The persistence of cavitation was accepted as the strongest indication for operation, but resection or thoracoplasty continued to be widely employed as an "insurance" measure for the future in patients with lesions of the solid focus type, or in whom cavities had closed with preliminary treatment.

As experience was gained with the prolonged administration of combinations of the antibacterial agents, their remarkable efficiency was more and more apparent. It became increasingly doubtful if " insurance" surgery was necessary, or if even the persistence of cavitation was a clear indication for operation. The present investigation was planned in an attempt to clarify these points.

\section{Material AND Method}

The material is drawn from a population of one million, and all patients coming under our care between January, 1954, and December, 1956, were reviewed for the present investigation.

The principal purpose was to establish whether "insurance" surgery was desirable for patients in whom cavities had already closed. We therefore included for study all patients with cavitary disease. and sputum containing tubercle bacilli, who had achieved sputum conversion and cavity closure during an arbitrary period of six months' antibacterial treatment; these were divided into two groups depending on whether or not surgery was carried out. At the onset we believed that surgery should normally be advised where cavitation persisted after six months' antibacterial treatment, and patients who had surgery for cavitated disease have not been studied.

It became clear, however, that a large number of patients in whom cavities persisted after the sputumb had become negative remained well in spite of noe having surgery, and these have been studied as a thirch group. Thus there were three groups of patients: Group A, patients with cavity closure after six months' antibacterial treatment, followed by surgery ; Group B, patients with cavity closure after six months, without surgery; Group C, patients with persisting cavity after six months, without surgery.

All were treated with two or three of the standard antibacterial agents in the régimes now accepted in Great Britain, except a small number who had intermittent streptomycin with daily P.A.S. or isoniazid for short periods early in the investigation. A substantial number had been given antibacterial treatment before coming under our care, but frequently no details were available of the treatment given.

After their initial treatment in hospital, where sputum was examined monthly by smear and culture, all patients had chest radiographs and sputum examinations at least quarterly. In the absence of sputum, laryngeal swabs were taken.

The criteria for bacterial resistance were growth of not less than 20 colonies on a Lowenstein-Jensen slope containing $5 \mu \mathrm{g}$. of isoniazid, $3 \mu \mathrm{g}$. of streptomycin, or $2 \mu \mathrm{g}$. of P.A.S. The level for isoniazid is perhaps high, but we chose it because at that time we were finding a number of strains which were growing in $1 \mu \mathrm{g}$. before treatment, and were uncertain of the significance of this. We maintained this criterion of $5 \mu \mathrm{g}$. throughout the investigation.

Relapse was accepted on convincing radiological evidence alone or on recovery of the tubercle bacillus 
by smear or culture from sputum or laryngeal swab on one or more occasions.

At the present time 390 patients have been followed from three to seven years from the start of chemotherapy: 60 patients were excluded who fulfilled the criteria except that we were unable to confirm a positive sputum at the onset, 37 have been followed from two to three years, 99 for three to four years, and 251 for over four years. Three patients died in under two years.

\section{RESULTS}

Age Distribution.-It is seen from Fig. 1 that there is no great difference between Group $A$ and $B$ as regards age distribution, the peak being from 15 to 34 years in each case, whereas in Group C the majority are aged over 35.

EXTENT OF Disease.-This is classified according to the number of zones involved (Foster-
Carter, Myers, Goddard, Young, and Benjamin, 1952) (Fig. 2).

One zone is shown in the left, two to three zones in the middle, and four or more zones in the righthand column. All three groups have a similar proportion with intermediate disease, but Group $\mathrm{C}$ has rather more patients with extensive disease and rather fewer with limited than the other two.

Total Cavity Diameter.-In Fig. 3 the lefthand column shows those with cavitation of less than $2 \mathrm{~cm}$., the middle with 2 to $5 \mathrm{~cm}$., and the right with more than $5 \mathrm{~cm}$. Again Group $\mathrm{C}$ has rather more patients with large cavities and fewer with small than the other two groups.

Considering the extent of disease and total cavity diameter together, it appears that Groups $A$ and $B$ are of overall comparable severity, for,

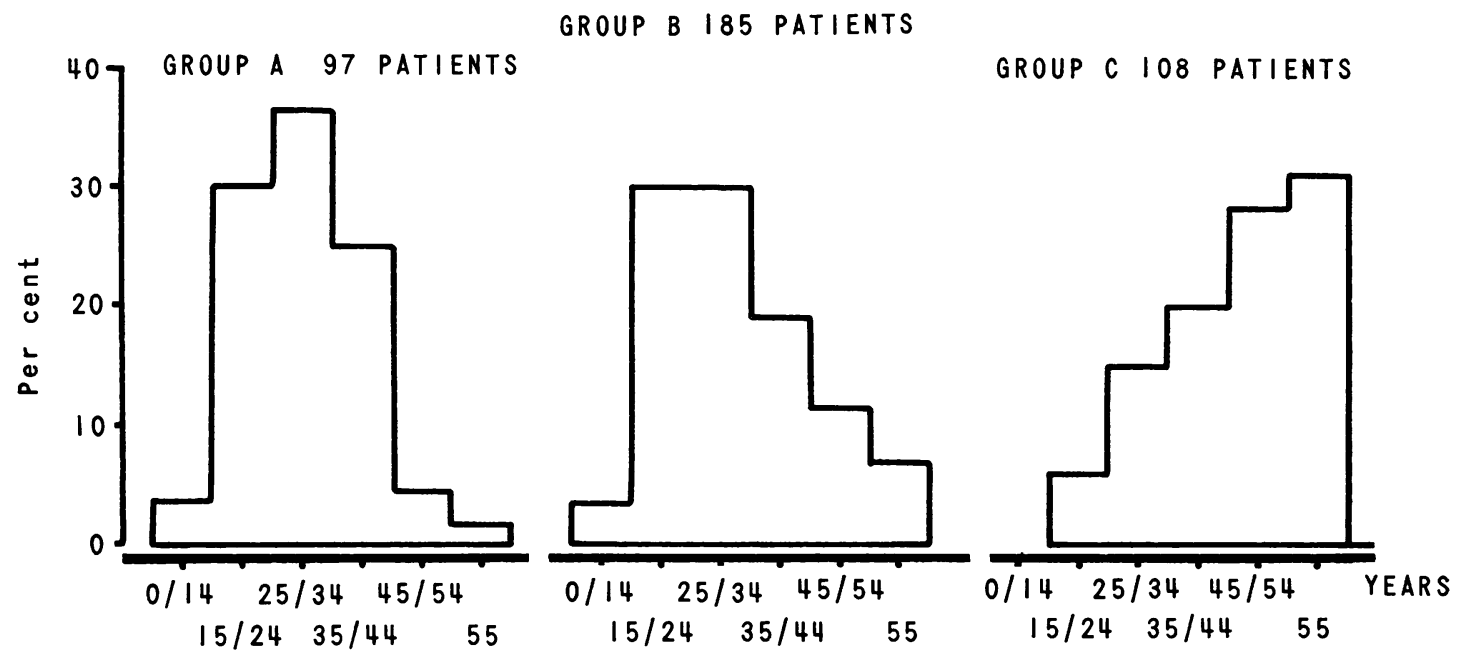

FIG. 1.--Age distribution of cases.

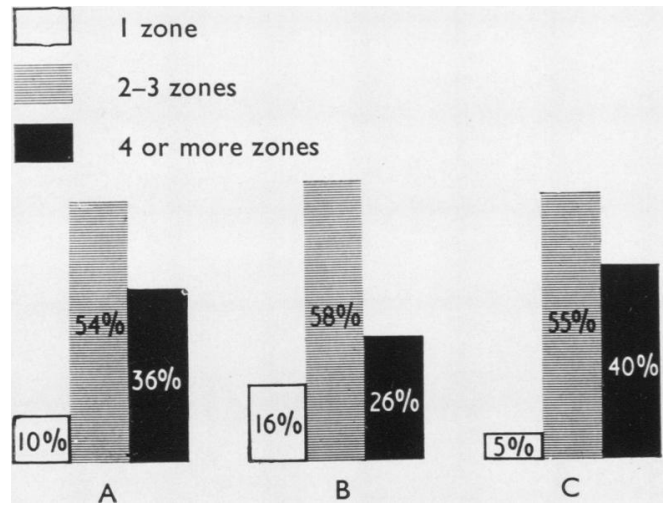

Fig. 2.-Extent of disease.

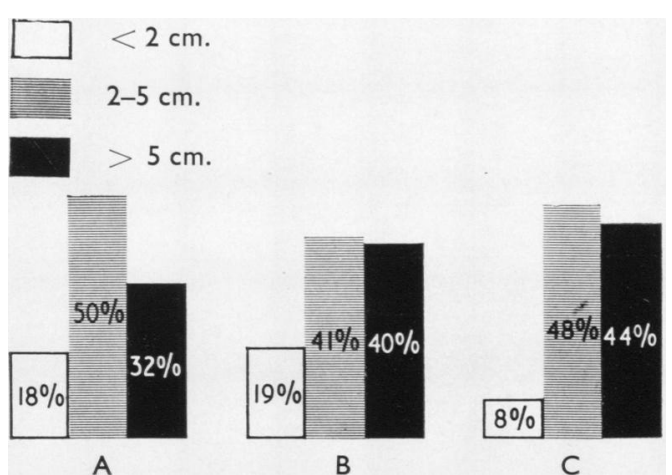

Fig. 3.-Total cavity diameter. 
whereas patients in the surgical Group A have slightly more extensive disease, in those in the medical Group B the cavities were somewhat larger. Patients in Group $\mathrm{C}$ have rather more advanced disease in both respects.

Overall Picture.-The overall results are shown in Table $I$.

\section{TABLE I}

390 PATIENTS FOLLOWED UP THREE TO SEVEN YEARS AFTER STARTING CHEMOTHERAPY

\begin{tabular}{|c|c|c|c|c|}
\hline & $\begin{array}{c}\text { Group A: } \\
97 \text { Patients } \\
\text { Cavity } \\
\text { Closure and } \\
\text { Surgery }\end{array}$ & \begin{tabular}{|} 
Group B: \\
185 Patients \\
Cavity \\
Closure with- \\
out Surgery
\end{tabular} & $\begin{array}{c}\text { Group C: } \\
\text { 108 Patients } \\
\text { Patent Cavity } \\
\text { and Negative } \\
\text { Sputum }\end{array}$ & Total \\
\hline $\begin{array}{ll}\text { Alive and well } & \ldots \\
\text { Working . } & \ldots \\
\text { Deaths } \ldots & \ldots\end{array}$ & $\begin{array}{c}96 \\
94 \\
1 \\
\text { (non-TB) }\end{array}$ & $\begin{array}{c}176 \\
167 \\
9 \\
\text { (non-TB) }\end{array}$ & \begin{tabular}{|c|}
99 \\
57 \\
8 \\
(1 tuberculo- \\
sis 7 not)
\end{tabular} & $\begin{array}{r}371 \\
318 \\
18\end{array}$ \\
\hline Relapses & Nil & 3 & $\begin{array}{c}\text { (1 died) (1 un- } \\
\text { der treat- } \\
\text { ment) }\end{array}$ & 6 \\
\hline
\end{tabular}

In Group A cavity closure was followed by surgery. Of a total of 97 patients, 96 are alive and well, with one (non-tuberculous) death. Ninetyfour of these patients are working and none has relapsed. Fifty were treated by resection of residual disease and 47 by thoracoplasty.

In Group B cavity closure was followed by antibacterial treatment alone. Of a total of 185 patients 175 are alive and well, and 167 of these are working. There have been nine deaths, all non-tuberculous, and three relapses.

In Group $C$ there was persistent cavitation with negative sputum, and surgery was not carried out. Ninety-eight patients out of a total of 108 are alive and well, though only 57 are working. These patients had more extensive disease and were older than those in the other two groups. Three patients have relapsed, one of whom died of tuberculosis. There were seven non-tuberculous deaths in this group, making eight in all.

The causes of death are analysed in Table II.

TABLE II

CAUSES OF DEATH

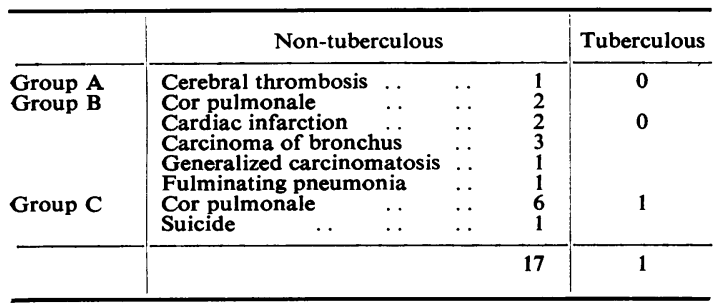

The one death in Group A was due to cerebral thrombosis three and a half years after surgery.

Of the nine deaths in Group B, two were due to cor pulmonale and heart failure, two to cardiac infarction, three to carcinoma of the bronchus, one to generalized carcinomatosis, and one to fulminating septic pneumonia which was confirmed at necropsy. In no instance was there evidence of reactivation of the tuberculosis.

In Group $C$ six patients died of cor pulmonale and heart failure without radiological or bacteriological evidence of reactivation of tuberculosis ; one committed suicide, and one died of progressive tuberculosis, the only tuberculous death in the whole series of 390 patients.

Taking the three groups together, eight died from cor pulmonale and heart failure, nine from unrelated causes, and one from active tuberculosis. Sixteen of the 18 patients died at home and necropsies were not obtained. The diagnosis in two of the patients who died of carcinoma was proved by biopsy, and necropsies were done on the patient who committed suicide and the patient with fulminating pneumonia. All the remainder had been seen recently by us and detailed information was obtained from the family doctor. I spite of the lack of necropsy evidence, we are satisfied that death was due to active tuberculosis in only one instance.

RELAPSES.-Details of the six patients who relapsed are given in Table III. There was none

TABLE III

RELAPSES

\begin{tabular}{|c|c|c|c|c|}
\hline & \multirow{2}{*}{ Criteria of Relapse } & \multicolumn{3}{|c|}{ Resistance Pattern } \\
\hline & & $\begin{array}{c}\text { Strepto- } \\
\text { mycin }\end{array}$ & P.A.S. & Isoniazid \\
\hline $\begin{array}{r}2 \\
3 \\
\text { Group C } 1 \\
2 \\
3\end{array}$ & $\begin{array}{l}\text { Reopened cavity, } \\
\text { sputum negative } \\
\text { Resected specimen, } \\
\text { smear positive, cul- } \\
\text { ture negative } \\
\text { Five positive cul- } \\
\text { tures } . \\
\text { Fresh cavity, two } \\
\text { positive cultures } \\
\text { Three positive cul- } \\
\text { tures (died) } \\
\text { Two positive cul- } \\
\text { tures } \\
\text { Three positive cul- } \\
\text { tures } .\end{array}$ & $\begin{array}{l}\text { Unknown } \\
\text { Sensitive } \\
\quad, \\
\text { Resistant } \\
\text { Sensitive } \\
\text { Resistant }\end{array}$ & $\begin{array}{c}\text { Unknown } \\
\text { Resistant } \\
\text { Sensitive } \\
\text { Resistant } \\
\qquad, \\
\text {,, }\end{array}$ & $\begin{array}{c}\text { Unknown } \\
\text { Resistant } \\
\text {," } \\
\text {,, } \\
\text {," }\end{array}$ \\
\hline
\end{tabular}

in the surgical group. In the first patient in Group B the cavity reopened, but the sputum remained negative. Subsequently lobectomy was done and the specimen was smear positive but culture negative, so that the bacterial resistance is unknown. The sputum of the second patient 
became positive on culture which showed resistance to P.A.S. and isoniazid 11 months after starting antibacterial treatment. The third patient relapsed with a fresh cavity and positive sputum eight months after finishing three years' treatment. The organisms were resistant to isoniazid.

Of the three patients in Group C, one had three positive cultures nine months after stopping a twoyear course of treatment. The organisms were resistant to all three agents, and she died shortly after leaving hospital at her own request while still culture-positive. The second produced positive cultures resistant to P.A.S. and isoniazid after three and a half years' continuous treatment, whilst the third relapsed two months after stopping three years' continuous treatment, the organisms showing resistance to all three agents.

Five of the six patients relapsing either had had treatment with a single agent or had failed to take their treatment regularly, and all showed some degree of bacterial resistance. The sixth, who had a radiological relapse only, would doubtless have done as well without surgery, as the specimen produced no viable organisms. From our experience with these patients, we think that the quality of antibacterial treatment is of more importance than its duration.

Our knowledge of many of the remaining, i.e., non-relapsing, patients is incomplete due to lack of information about pre-treatment sensitivities and about antibacterial treatment given before they came under our care.

Duration of Antibacterial Treatment.-The duration of treatment is shown in Fig. 4 and was

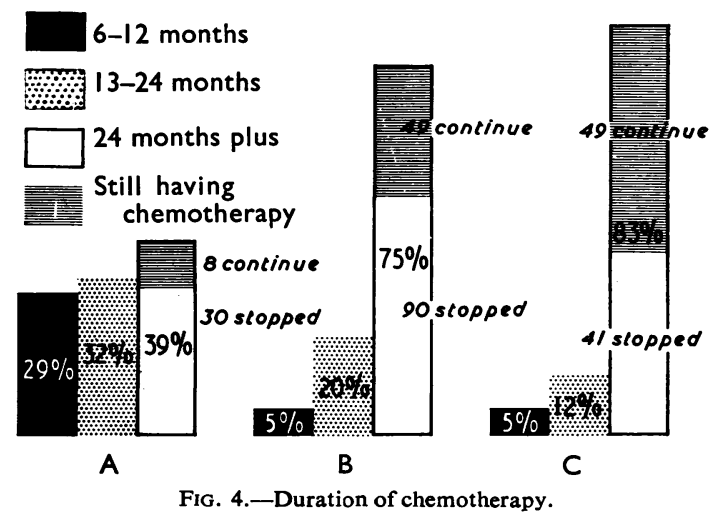

not decided on a random basis but according to our clinical policy at the time. The left-hand column shows those having less than 12 months', the middle 13-24, and the right more than 24 months' treatment. One-third of the surgical group had less than a year's treatment in all, compared with only $5 \%$ in the non-surgical groups; three-quarters of the latter have continued treatment for over two years. At present, 184 of the 390 patients have discontinued treatment for two years or more.

\section{Discussion}

The present study deals with patients who were selected on the grounds of their response to antibacterial therapy because at the end of six months' treatment the sputum of all had become free of tubercle bacilli. The series includes a high proportion of all the patients admitted under our care with cavitated disease and sputum containing tubercle bacilli. We excluded patients who underwent operation for persistent cavitation and patients whose sputum contained tubercle bacilli in spite of prolonged treatment, most of whom proved to be infected with resistant organisms.

The information available on the sensitivities of the organisms before treatment is incomplete, and probably not entirely reliable by present standards. Some patients had had unsatisfactory antibacterial treatment in previous years and their organisms might have developed a degree of resistance to one or more of the agents, but the satisfactory response to treatment suggests that the organisms were sensitive in the great majority of patients. The organisms of the five patients who relapsed bacteriologically all showed varying degrees of resistance.

INDICATIONS FOR SURGERY.-The indications for operation accepted in these patients were rather flexible and also varied to some extent from one area to another. They were clearly very wide in 1955 when the number of operations performed was 47. However, with increasing confidence in antibacterial treatment alone, 27 operations were carried out in 1956 and only four in 1957. In a further 16 patients, operation was advised but refused, and these are included in the medical series.

Extensive disease, slow closure of cavities, large residual solid foci, and the presence of considerable tracheal and mediastinal shift with consequent distension of the diseased opposite lung, were all frequently considered to be conditions requiring operation in the early years. Social factors were also taken into account in reaching a decision. As the remarkable efficiency of long-term antibacterial treatment became apparent, there only remained as generally accepted indications the suspected but unproven presence of resistant 
tubercle bacilli, and the inability or unwillingness of patients to continue a satisfactory drug régime due either to toxic or allergic reactions or to temperament.

Our findings suggest that little has been gained by operation in these patients. Although the excellent surgical results were obtained with shorter periods of antibacterial treatment, the patients were, on the average, in hospital two months longer than the Group B medically treated patients (nine months against seven), so that they had an additional period of closely supervised treatment. The satisfactory results in Group B conform with the findings of Ross and Kay (1956), who studied patients in whom cavities had closed during antibacterial treatment and found no relapses in those who had continued drug treatment for more than six months after cavity closure.

Patients with Persistent Cavitation and Negative Sputum.-More than half of the patients with open cavities (Group C) were considered to be too old or unfit for surgery. Nine refused to come into hospital and nine refused operation. The remainder (about a quarter) were treated medically because the results of antibacterial treatment were so encouraging that it was doubted whether operation was necessary.

Until recently, the outlook for patients with persistent cavitation would have been considered unfavourable in spite of the achievement of sputum conversion. Not only was the average age of these patients considerably higher than in the other groups, but the disease was more extensive, the cavities were larger and they failed to close with prolonged antibacterial treatment and bed rest. In many of these patients the indications for surgery would have been considered very strong, and the group provides an exacting test for medical treatment. In spite of this the results were hardly less satisfactory than those obtained in the other two groups. All three patients who relapsed had had unsatisfactory régimes in the early stages and ultimately produced drug-resistant organisms in the sputum. These very encouraging results are in close accord with those reported in Great Britain by Douglas and Horne (1956), who treated six patients with persistent cavitation, and with those of Wilson, Doyle, and Gardiner (1958), who treated 40 similar patients using optimum drug régimes. The sputum of both these groups of patients became persistently negative for tubercle bacilli, and no relapses had occurred at that time.
Recent reports from the U.S.A. have been less encouraging. Raleigh (1957) found a $50 \%$ relapse rate during a $2 \frac{1}{2}$-year period of observation of 123 medically treated "open-negative" patients who had had eight to 17 months' antibacterial treatment (mean 16 months). Corpe and Blalock (1958) reported an $8.8 \%$ relapse rate during a three to 48 months' observation of 159 patients whose sputum had not contained tubercle bacilli for at least a year, and had been treated with prolonged antibacterial treatment. The exact régimes of antibacterial treatment are not defined in these papers.

The markedly different results in the two series can probably be explained by the fact that some of Raleigh's patients started treatment as early as 1950 , when régimes of antibacterial treatment now considered to be unsatisfactory were in frequent use, and patients were included whose sputum or gastric cultures had been negative for tubercle bacilli for only three months. In contrast, the earliest patients in Corpe's series began treatment in 1953 and the sputum was required to be negative for a year.

A theoretical case can perhaps be made out for surgical closure or removal of these open cavities on the grounds that haemorrhage or secondar infection might occur. Both these complications appear to be very rare and have not occurred in our patients. Corpe and Blalock reported no instance of suppuration or haemorrhage during their observation of 159 patients.

Régimes and Duration of Treatment.-The fundamental facts concerning the dosage and combination of drugs necessary to prevent the development of bacterial resistance were firmly $\underset{x}{ }$ established by Medical Research Council trials $\dot{\sigma}$ $(1950,1952,1953$, and 1955) and have been re-emphasized by Crofton (1959). It is now $\delta$ generally accepted in Britain that it is essential to $₹$ give daily streptomycin with isoniazid or P.A.S., 음 or, alternatively, daily isoniazid and P.A.S. Many $D$ workers prefer to give all three agents together in the early months while the results of bacterial $\bar{N}$ sensitivity tests are awaited, since resistance could 0 develop on a two-drug régime if the bacilli were $\tilde{O}$ already resistant to one of those in use. This has $\underset{\mathrm{W}}{\mathrm{N}}$ been our policy in recent years.

Long-term antibacterial treatment was firsto widely adopted in the U.S.A. where, by 1951, the duration of twice-weekly streptomycin and P.A.S. $\stackrel{?}{?}$ therapy generally in use was 12 months or more 7 (Mitchell and Bell, 1958). In 1955, Hoyle, $\stackrel{\circ}{\circ}$ Nicholson, and Dawson in Britain described the 
early results of treating 142 patients with antituberculous drugs for at least nine months, and drew attention to the need for prolonged treatment. In a report concerning the later progress of this group, together with that of 51 other patients fulfilling the requirements for inclusion, Batten, Turner-Warwick, Hoyle, and Nicholson (1960), while agreeing that the length of treatment required remains obscure, give their view that all cases of pulmonary tuberculosis, even when very slight, should receive at least two years' drug therapy.

Studies of Resected Specimens.-A good indication regarding the length of treatment required for the various types of tuberculous lesions is provided by studies of the histology and bacteriology of resected specimens, duly correlated with the results of tests of bacterial sensitivity and with the type and duration of treatment employed.

Stewart, Turnbull, and Macgregor (1956) in a study of resected specimens found that, in patients with sensitive tubercle bacilli and caseous foci or cavitation, the longer the duration of effective treatment the less the likelihood of viable organisms persisting in the lesion. No viable bacilli were obtained from either type of lesion where treatment had been continued for 18 months or more. There was a close correlation between the healing of cavity walls and the results of bacteriological examination of the lesion. In contrast, in the group with sputum containing drug-resistant tubercle bacilli, $93-100 \%$ of the lesions contained viable bacilli regardless of the length of treatment. Although caseous foci were sterilized more readily than cavities, it was concluded that at least 12 to 18 months' treatment was essential in both conditions. Eade, Harrison, Large, Mackay-Dick, Reid, and Riddell (1959) studied the bacteriology of resected specimens from the lungs of 59 Gurkha soldiers after 10 to 25 months' treatment. In general they found a progressive decrease in positive cultures with increasing duration of chemotherapy. Five patients had persistent cavitation after periods of chemotherapy of more than nine months, and the resected specimens of three contained viable tubercle bacilli. The pre-operative laryngeal swab cultures of two of these, however, grew resistant tubercle bacilli. They considered that these findings, together with those of Keers, Riddell, and Reid (1956) and of Bell, Decker, and Raleigh (1957), constitute a strong argument for resection in these "open-negative" patients. The régimes of treatment used in many patients in these series, however, have not been those generally recognized to be essential at the present time. Cotter, Foreman, and Seal (1958) studied the resected specimens of 218 patients and found acid-fast bacilli in $65 \%$ of the specimens, but tubercle bacilli were grown on culture in only $12 \%$. After satisfactory treatment for at least eight months (average $12 \frac{1}{2}$ months), no viable bacilli were found, whereas after long, indifferent, and bad régimes $12-18 \%$ of the resection specimens contained viable bacilli. No positive cultures were obtained from five resected specimens containing open cavities from patients who had had good antibacterial treatment. It was concluded that the development of bacterial resistance was an important factor in the recovery of bacilli from resected lesions, and that this was associated with bad antibacterial treatment.

Edge and Bottrill (1959) found that $15 \%$ of resected specimens contained viable tubercle bacilli after a minimum period of six months of good treatment, whereas viable bacilli were found in $52 \%$ of specimens from 75 patients who had had unsatisfactory régimes. They found the sensitivity levels of the organisms from the preoperative cultures and from the resected specimens to be remarkably consistent, and they confirm the close relationship of resistance with the persistence of viable bacilli, and the very frequent association of both with unsatisfactory treatment.

These papers, therefore, suggest that sterilization of tuberculous lesions can be achieved, provided that the organisms are sensitive to the antibacterial agents, and provided that these are used in optimum dosage and combination and maintained for a long time: a minimum period of 18 months seems to be essential. Our own policy latterly has been to continue treatment for three years in cases of moderate severity and up to five years for advanced disease. The present dilemma as to when to stop treatment can evidently only be decided finally by many years' follow-up of different treatment groups.

The Future Place of Surgical Treatment.The clinical results in the present series, which are in close accord with those previously published by Ross and Kay (1956) and Wilson et al. (1958), may suggest that medical treatment in these circumstances would always be successful, and that surgery would, therefore, be contraindicated. This sweeping conclusion is possibly premature and certainly an oversimplification. Not only is the period of observation in all published series 
too short to be certain that relapses may not still occur, but it is also impossible to be certain whether or not resistant organisms are present if tubercle bacilli cannot be recovered from the patient. The history of previous unsatisfactory treatment may lead one to suspect their presence, but only prolonged treatment and observation may prove the point. Even in the absence of previous chemotherapy resistant bacilli may be present, since exogenous infection with these organisms may occur in 3 to $5 \%$ of patients (Fox, Wiener, Mitchison, Selkon, and Sutherland, 1957).

The danger of the presence of unsuspected resistant organisms is well illustrated by Edge and Bottrill (1959), who found that the resected specimens contained resistant organisms in four out of 170 patients, although the pre-operative cultures had been persistently negative for tubercle bacilli. They concluded that without surgery there would have been a high risk of relapse in these patients.

Problems in Maintaining Satisfactory AntiBaCterial TREATMENT.-Difficulties may arise in the maintenance of a satisfactory régime due either to toxic or allergic reactions or to the temperament of the patient. These factors can nearly always be controlled in hospital, but, once the patient has been discharged home, trouble not infrequently arises. Dixon, Stradling, and Wootton (1957) and Wynn-Williams and Arris (1958) have shown that ferric-chloride tests of the urine of out-patients supposedly taking P.A.S. were negative in $50 \%$ and $49 \%$ of their patients respectively.

In the present series this aspect was not fully investigated in the early years, but recently tests on 140 of these patients have shown the presence of P.A.S. in the urine of $66 \%$. It is clearly essential to supervise the patient's treatment as closely as possible after leaving hospital.

\section{CONCLUSIONS}

In patients in whom the lung cavities have closed and sputum has ceased to contain tubercle bacilli during six months' antibacterial treatment, there is nothing to be gained from "insurance" surgery, provided the bacteria were initially fully sensitive to the main antibacterial agents and provided adequate treatment with these agents is maintained for at least 18 months. In the same way, in those patients in whom cavities have remained open and sputum has ceased to contain tubercle bacilli during six months' antibacterial treatment, there is probably nothing to be gained by surgical operation, provided the bacteria were originally fully sensitive. The length of antibacterial treatment necessary in this group may well be several years.

Medical treatment using optimum régimes for a period of at least 18 months is indicated in all patients with pulmonary tuberculosis caused by bacilli sensitive to the antibacterial agents. Surgical treatment, although carrying an increased risk in these circumstances, is probably indicated only when infection with resistant bacilli is proved. It may also be indicated for patients who cannot maintain an adequate régime of chemotherapy due to drug reactions or temperamental difficulties. In patients where the presence of resistant organisms can be suspected but remains unproven, it seems reasonable to await the outcome of medical treatment before advising for or against operation. Only permanent observation of medically treated patients will show whether or not other indications for surgical treatment will become re-established.

\section{SUMMARY}

Three hundred and ninety patients with cavitating pulmonary tuberculosis with tubercle bacilli in the sputum were divided into three groups according to treatment.

In all patients, the sputum converted to negative within six months of starting treatment.

All the relapses occurred in patients who had been treated with unsatisfactory antibacterial régimes in the earlier stages.

All patients have been followed from three to seven years from the start of antibacterial treatment. During this period 18 have died, eight from pulmonary heart disease, nine from unrelated causes, and only one from active tuberculosis.

Our thanks are due to Mr. James Glennie and Mr. Percy Jewsbury, who operated on the patients in Group A, and to Dr. D. E. Bottrill, who did most of the bacteriological work.

The expenses of the work were defrayed by a grant made to one of us (J.R.E.) from the endowment funds of the Manchester Regional Hospital Board.

It is a great pleasure to acknowledge our indebtedness to Mrs. Shaun Cleave for her invaluable secretarial assistance.

\section{REFERENCES}

Batten, J., Turner-Warwick, M., Hoyle, C., and Nicholson, H. (1960). Lancet, 1, 409.

Bell, J. W., Decker, A. M., and Raleigh, J. W. (1957). Amer. Rev. Tuberc., 75, 538 
Bickford, B. J., Edwards, F. R., Esplen, J. R., Gifford, J. G., and Thomas, O. F. (1952). Thorax, 7, 310.

Bottrill, D. E., and Edge, J. R. (1957). Tubercle (Lond.), 38, 303.

Corpe, R. F., and Blalock, F. A. (1958). Amer. Rev. Tuberc., 77, 764. Cotter, D. J., Foreman, H. M., and Seal, R. M. E. (1958). Thorax, 13,150 .

Crofton, J. (1959). Brit. med. J.,1, 1610.

Dixon, W. M., Stradling, P., and Wootton, I. D. P. (1957). Lancet, 2, 871 .

Douglas, A. C., and Horne, N. W. (1956). Brit. med. J., 1, 375.

Eade, A. W. T., Harrison, G. K., Large, S. E., Mackay-Dick, J., Reid, L., and Riddell, R. W. (1959). Thorax, 14, 104.

Edge, J. R., and Bottrill, D. E. (1959). Brit. med. J., 1, 276.

Foster-Carter, A. F., Myers, M., Goddard, D. L. H., Young, F. H., and Benjamin, B. (1952). Brompton Hosp. Rep., 21, 1.

Fox, W., Wiener, A., Mitchison, D. A., Selkon, J. B., and Sutherland, I. (1957). Tubercle (Lond.), 38, 71.

Hoyle, C., Nicholson, H., and Dawson, J. (1955). Lancet, 2, 1310.

Keers, R. Y., Riddell, R. W., and Reid, L. (1956). Tubercle (Lond.), 37, 404 .
Lehmann, J. (1946). Lancet, 1, 15.

Medical Research Council (1950). Brit. med. J., 2, 1073.

— (1952). Ibid., 1, 1157.

(1953). Ibid., 2, 1005.

- (1955). Ibid., 1, 435.

Mitchell, R. S., and Bell, J. C. (1958). Modern Chemotherapy of Tuberculosis. Medical Encyclopedia, New York.

Raleigh, J. W. (1957). Amer. Rev. Tuberc., 76, 540.

Robitzek, E. H., and Selikoff, I. J. (1952). Ibid., 65, 402.

Ross, J. D., and Kay, D. T. (1956). Thorax, 11, 1.

Schatz, A., Bugie, E., and Waksman, S. A. (1944). Proc. Soc. exp. Biol. (N.Y.), 55, 66.

Stewart, S. M., Turnbull, F. W. A., and Macgregor, A. R. (1956). Tubercle (Lond.), 37, 388.

Thompson, H. T., Savage, T., and Rosser, T. H. L. (1954). Thorax, $9,1$.

Wilson, T. M., Doyle, L., and Gardiner, M. P. (1958). Brit. med. J., $2,87$.

Wynn-Williams, N., and Arris, M. (1958). Tubercle (Lond.), 39, 138. 